\title{
Estimate the Meaning-Time-To-Failure of LED driver using Numerical simulation
}

\author{
Si Tien Nguyen $1{ }^{*}$, An Dinh Pham ${ }^{2}$ \\ ${ }^{1}$ Hanoi University of Mining and Geology, Hanoi, Vietnam \\ ${ }^{2}$ Advanced Technology Joint Stock Company, Hanoi, Vietnam
}

\begin{abstract}
ARTICLE INFO
ABSTRACT

Article history:

Received $25^{\text {th }}$ July 2021

Revised 26 $6^{\text {th }}$ Oct. 2021

Accepted 25 $5^{\text {th }}$ Nov. 2021

Keywords:

Electro-thermal,

LED driver,

Meaning-Time-To-Failure,

MTTF.

The Meaning-Time-To-Failure (MTTP), also known as Electromigration Analysis is an estimation of product life. Light-Emitting Diodes (LEDs) are usually driven by constant current switched-mode power supplies, which are invented early than LEDs for lighting applications. While LEDs themselves are extremely reliable and have a long lifetime, the electronic LED drivers in experiment usually fail due to overheating causing Printed Circuit Boards (PCBs) explosion, inability provide current/voltage input to the LEDs over their whole lifetime. This paper proposes a numerical simulation method to predict fault location on PCB of LED driver based on 2-way coupling electro-thermal multiphysic analysis, then applies the analytic models to calculate the time to failure of the points on PCB of LED drivers. The procedures can be applied to assist managers in assessing risk and making LED-based lighting system reliability decisions.
\end{abstract}

Copyright (C) 2021 Hanoi University of Mining and Geology. All rights reserved.

\section{Introduction}

An LED lighting system (lamp or luminaire) is mainly consisted of an LED power supply (a driver), a body, optical parts, and heat dissipation components. The LED light source often has a lifetime as long as 25,000 - 100,000 hours (W. D. van Driel et al., 2012).

Many studies have focused on the degradation analysis of LEDs only, without taking consideration of the LED driver's degradation (J. Huang et al., 2015; F. Haghighi et al., 2015; C.

\section{${ }^{*}$ Corresponding author}

E-mail: nguyentiensi@humg.edu.vn

DOI: 10.46326/JMES.2021.62(6).09
Quian et al., 2016). Meanwhile, the majority of LED lights are often faulty due to the driver circuit (Pradeep Lall et al., 2015; Michael Riebling et al., 2011). There are many topologies of led driver such as buck/boost, Cuk, SEPIC (Single-Ended Primary-Inductor Converter) (non-isolated switching power supply), fly-back, half/fullbridge, push-pull converter (isolated switching power supply). As a result of switching phenomenon, the junction temperatures of LEDs, MOSFETs and power diodes in driver rise significantly (R. Wu et al., 2013; S. Lan et al., 2014), leading to a much shorter MTTF, and faster luminous flux depreciation. In this paper, a multiphysics simulation method has been used to predict the driver's MTTF. 
Figure 1 displays the structure of low-power LED bulb:

- Light board: The lamp circuit, the most important part of the lamp includes the LED chip and the accessories that help the LED chip creat light.

- Power supply: Driver circuit, providing power for LED and help LED chip to work stably.

- Lampshare: The part that protects and transmits the light of the LED chip to the environment.

- Light body: The plastic or aluminum part that protects the lower part of the LED

- Lamp holder and thimble: Lamp holder (usually E14 and E27).

Figure 2 displays the general methodology which integrates the electronic-thermal simulation. Starting from the schematic design, simulate the electronic circuit and compare the simulation results with the actual measurement results on the real driver circuit. When the simulation results are close to the experimental results, plot the current density map, from which plot the heat distribution map. Finally apply analytic formula to predict MTTF of LED driver.

\section{Electronics Model}

A temperature-dependent model for LED light source is considered in the circuit model in Figures 3.1 and 3.2. Topology of driver LED is $\mathrm{AC} / \mathrm{DC}$ buck converter.

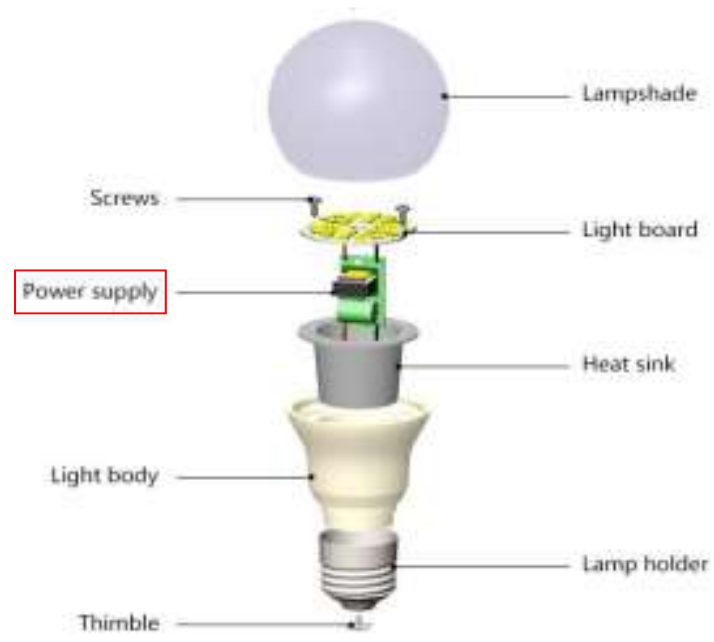

Figure 1. The structure of low-power LED bulb.

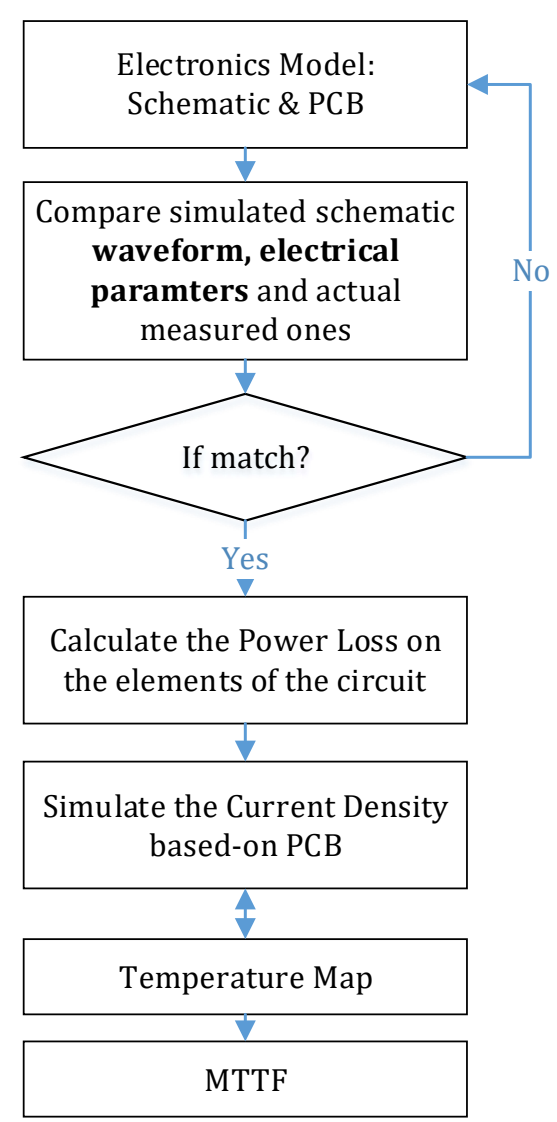

Figure 2. General Methodology of the Proposed Approach.

In this model, CS7210S is a high precision constant current LED driver chip is suitable for the full range $85 \div 265 \mathrm{~V} \mathrm{AC}$ input voltage, nonisolated Buck LED constant current power supply system. CS7210S integrated $500 \mathrm{~V}$ power MOSFET.

Compare simulation results and measured results at conditions:

- Normal Load;

- Ambient Temperature: $25^{\circ} \mathrm{C}$;

- Input Voltage: $220 \mathrm{VAC} / 50 \mathrm{~Hz}$ for error < $3 \%$ as in Table 1 .

Table 1. Electric Parameters.

\begin{tabular}{|c|c|c|c|}
\hline TT & Parameter & Simulation & Experiment \\
\hline 1 & Vout $(\mathrm{V})$ & $59.75 \mathrm{~V}$ & $59.24 \mathrm{~V}$ \\
\hline 2 & Iout $(\mathrm{mA})$ & $137.4 \mathrm{~mA}$ & $136.2 \mathrm{~mA}$ \\
\hline 3 & Pout $(\mathrm{W})$ & $8.25 \mathrm{~W}$ & $8.09 \mathrm{~W}$ \\
\hline 4 & Performance & $92.4 \%$ & $91.2 \%$ \\
\hline 5 & Power loss & $0.66 \mathrm{~W}$ & $0.68 \mathrm{~W}$ \\
\hline
\end{tabular}

The figures 4.1 and 4.2 display the current and 


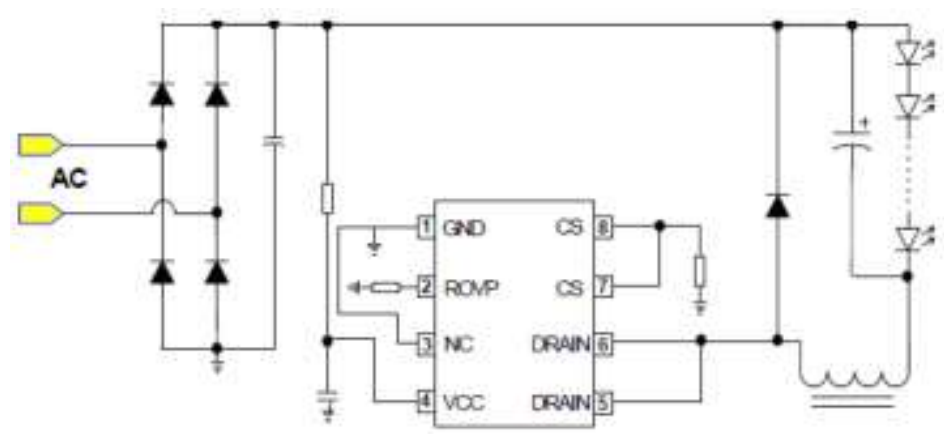

Figure 3.1. The principle diagram of LED driver.

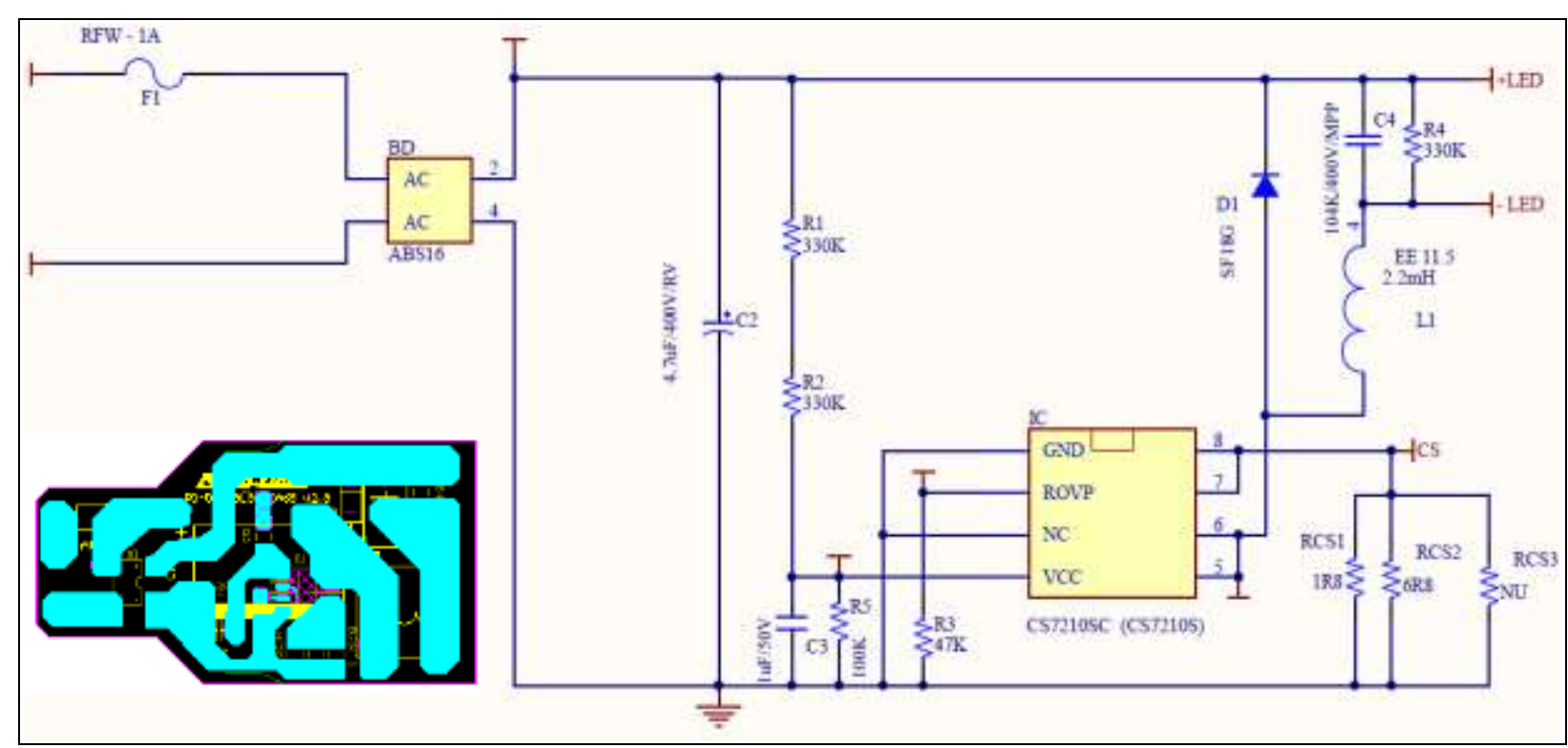

Figure 3.2. The Circuit and Layout of the LED driver.

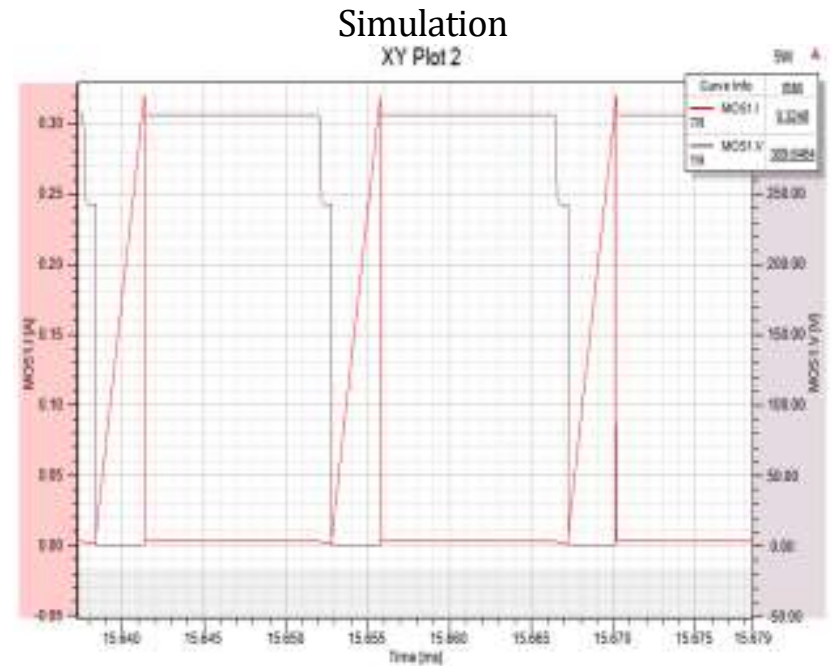

(a)

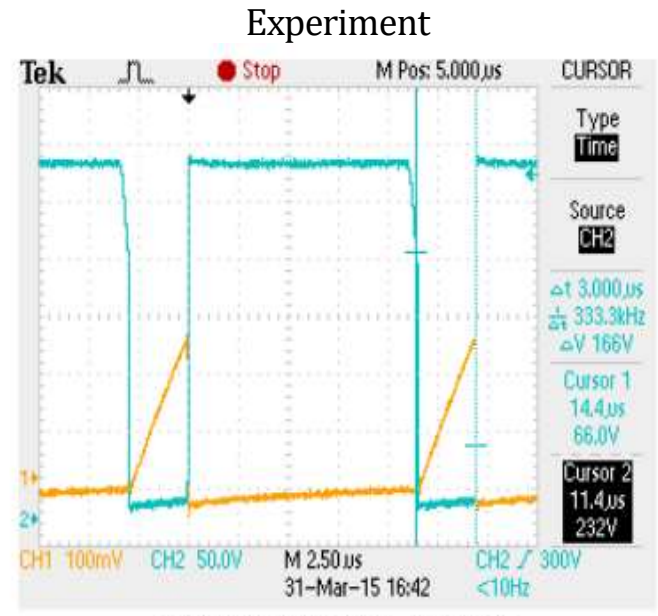

TDS 2012C-4:03:29 CH 31/03/2015

(b)

Figure 4.1. Waveform of Ids \& Uds on MOSFET. (a) Ids = $324.8 \mathrm{~mA}$; Uds = 309.6 V; (b) Ids=312 mA; Uds = $314 \mathrm{~V}$. 

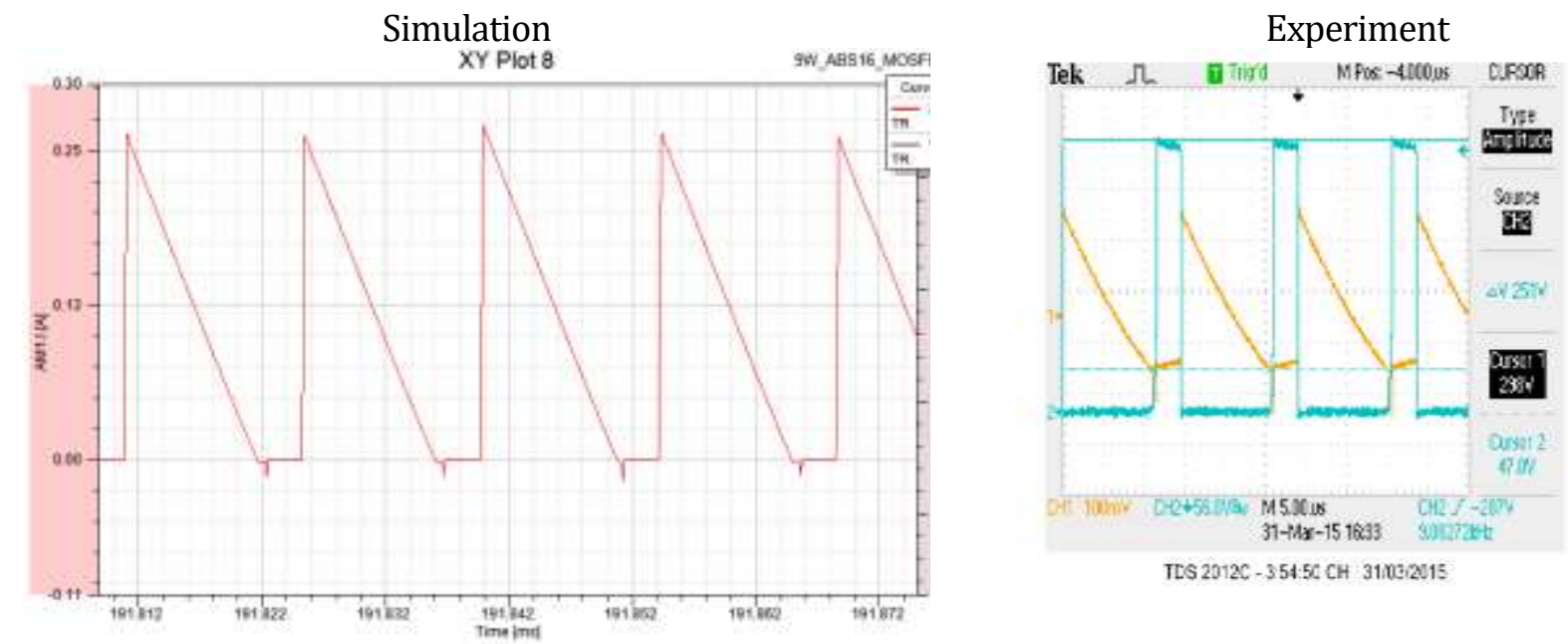

Figure 4.2. Waveform of Id \& Uka on diode D1.

voltage waveforms on the mosfet and diode components in the led driver circuit. The results show that the simulation results are close to the measurement results on the actual circuit.

\section{Thermal Model}

The heat sources come from the LEDs and the driver's components. By the multi-physics simulation between electronics and thermal, the results of the current density on the trace of the PCB and the heat distribution are shown.

The electric-thermal couple bidirectional analysis (2-way coupling) can be done in Figure 5. Figure 6 shows the power loss calculated the same as value in Table 1 .

The maximum temperature of the solution is $58.3^{\circ} \mathrm{C}$ when the temperature of enviroment is $25^{\circ} \mathrm{C}$. When increasing the temperature from 25 to $40^{\circ} \mathrm{C}$, the maximum temperature of circuit board increases up to $76^{\circ} \mathrm{C}$. The highest temperature position is at the IC integrated MOSFET and switching-diode, choke coil (inductor L1). This is consistent with actual heat measurement.

Black's Equation is a mathematical model for the mean time to failure (MTTF) of a semiconductor circuit due to electromigration: a phenomenon of molecular rearrangement (movement) in the solid phase caused by an electromagnetic field (Black J.R., 1969; R. L. de Orio, 2010).

This equation is:

$$
M T T F=A j^{-n} e^{\left(\frac{E_{a}}{k T}\right)}
$$

where: A is an experimental constant;

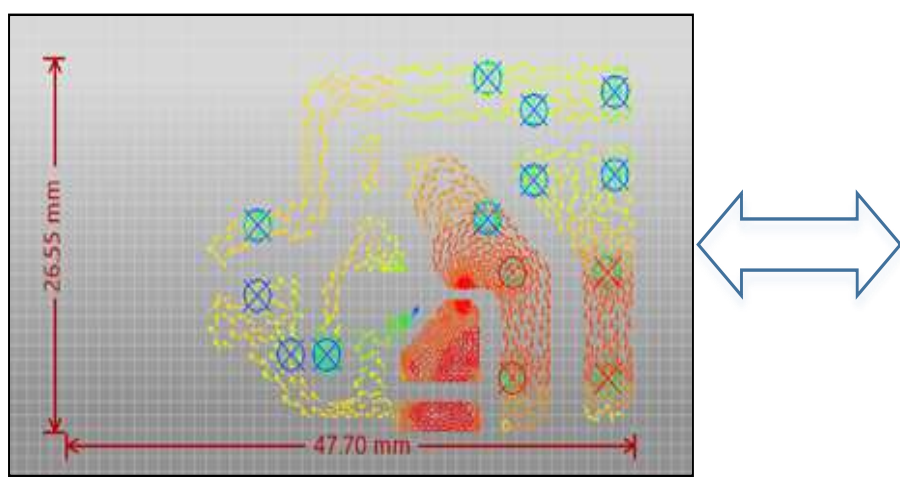

Current Density $\left(A / m^{2}\right)$

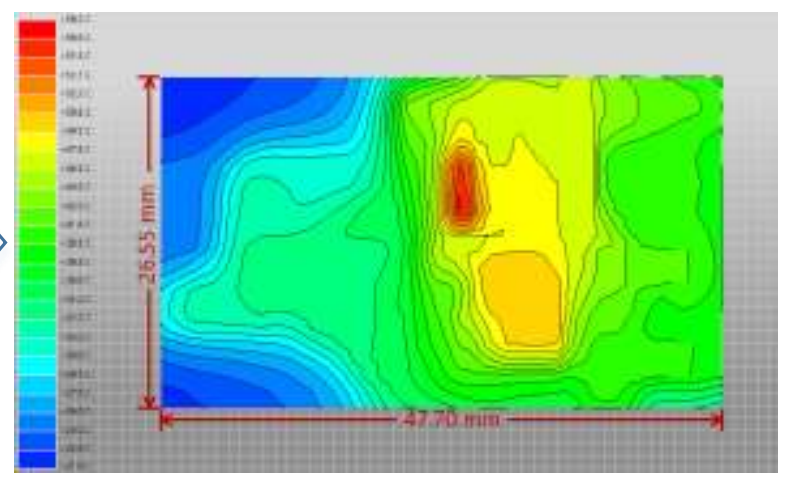

Temperature

Figure 5. The electro-thermal 2-way coupling procedure 1. 


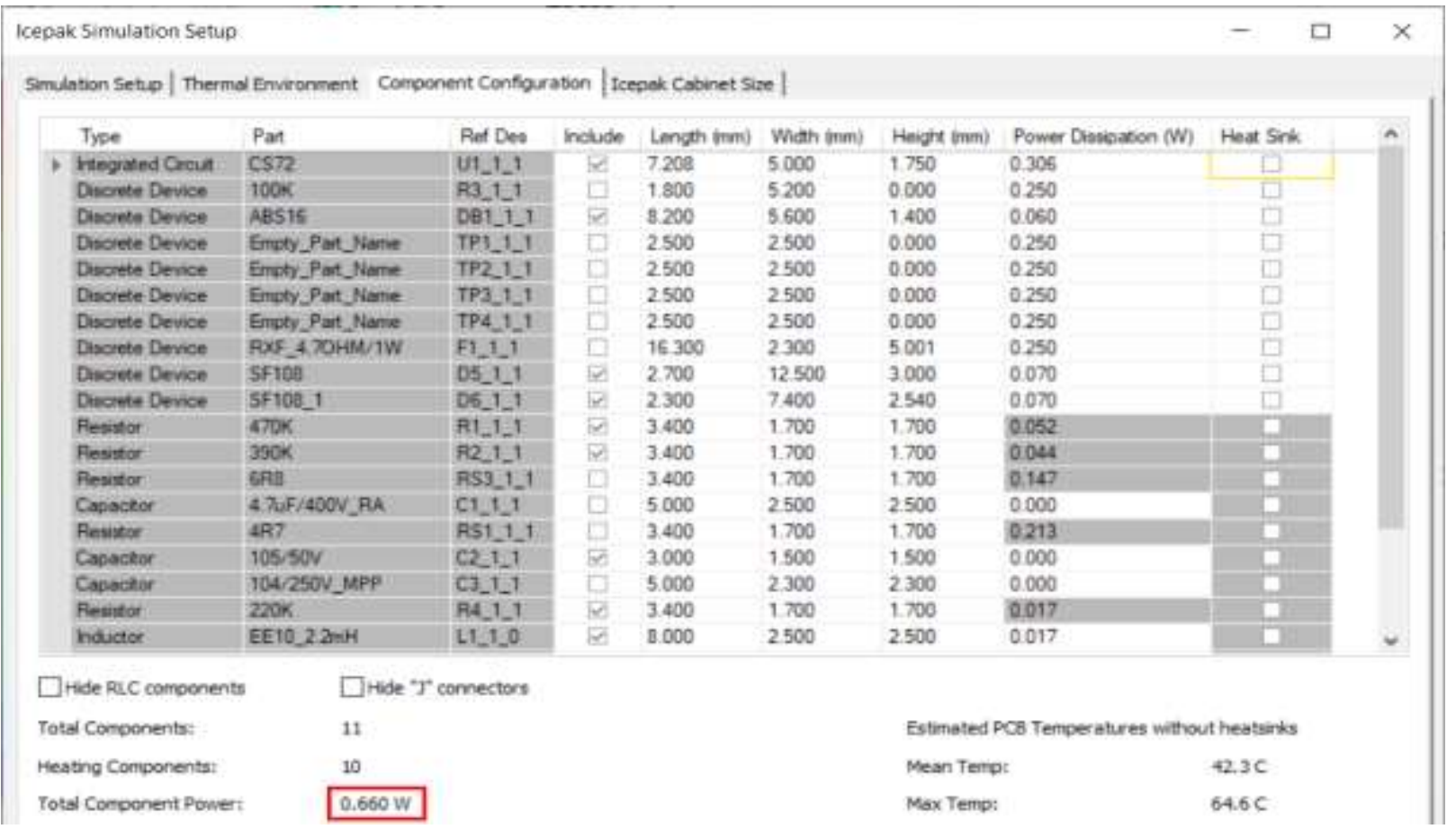

Figure 6. The power loss.

$\mathrm{j}$ is the current density;

$\mathrm{n}$ is a value between 1 and 2 .

$n$ is close to 1 when current density is low ( $\leq$ $0.1 \mathrm{MA} / \mathrm{cm}^{2}$ ) and gradually trends toward 2 as current density increases.

$$
\begin{aligned}
& \mathrm{n}=1.5 \text { for } 0.1 \mathrm{MA} / \mathrm{cm}^{2}<j<1 \mathrm{MA} / \mathrm{cm}^{2} ; \\
& \mathrm{n}=2 \text { for } \mathrm{j} \geq 1 \mathrm{MA} / \mathrm{cm}^{2} ; \\
& \text { Ea is the activation energy; }
\end{aligned}
$$

$\mathrm{k}$ is the Boltzmann Constant;

$\mathrm{k}=1.38 \times 10^{-23} \mathrm{~m}^{2} \mathrm{~kg} \mathrm{~s}^{-2} \mathrm{~K}^{-1}$;

$\mathrm{T}$ is the temperature in Kelvin.

Black's equation is to estimate the time of use of the conductor's electron migration (conductor damage, product hang-up) through Ea (active Energy activation energy) and $\mathrm{n}$ (experience factor) to take into account the DC current density

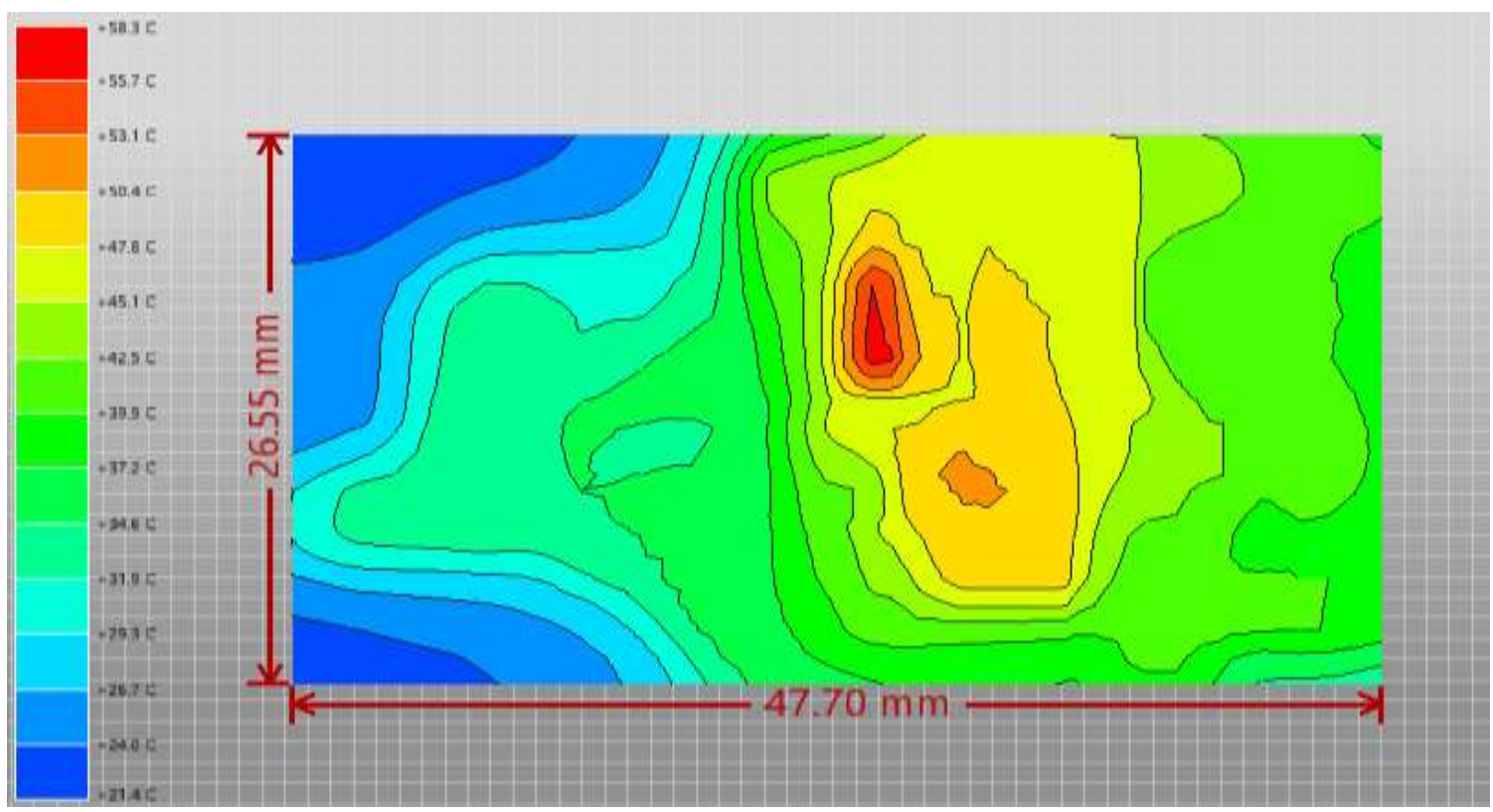

(a) at $25^{\circ} \mathrm{C}$ ambient temperature 


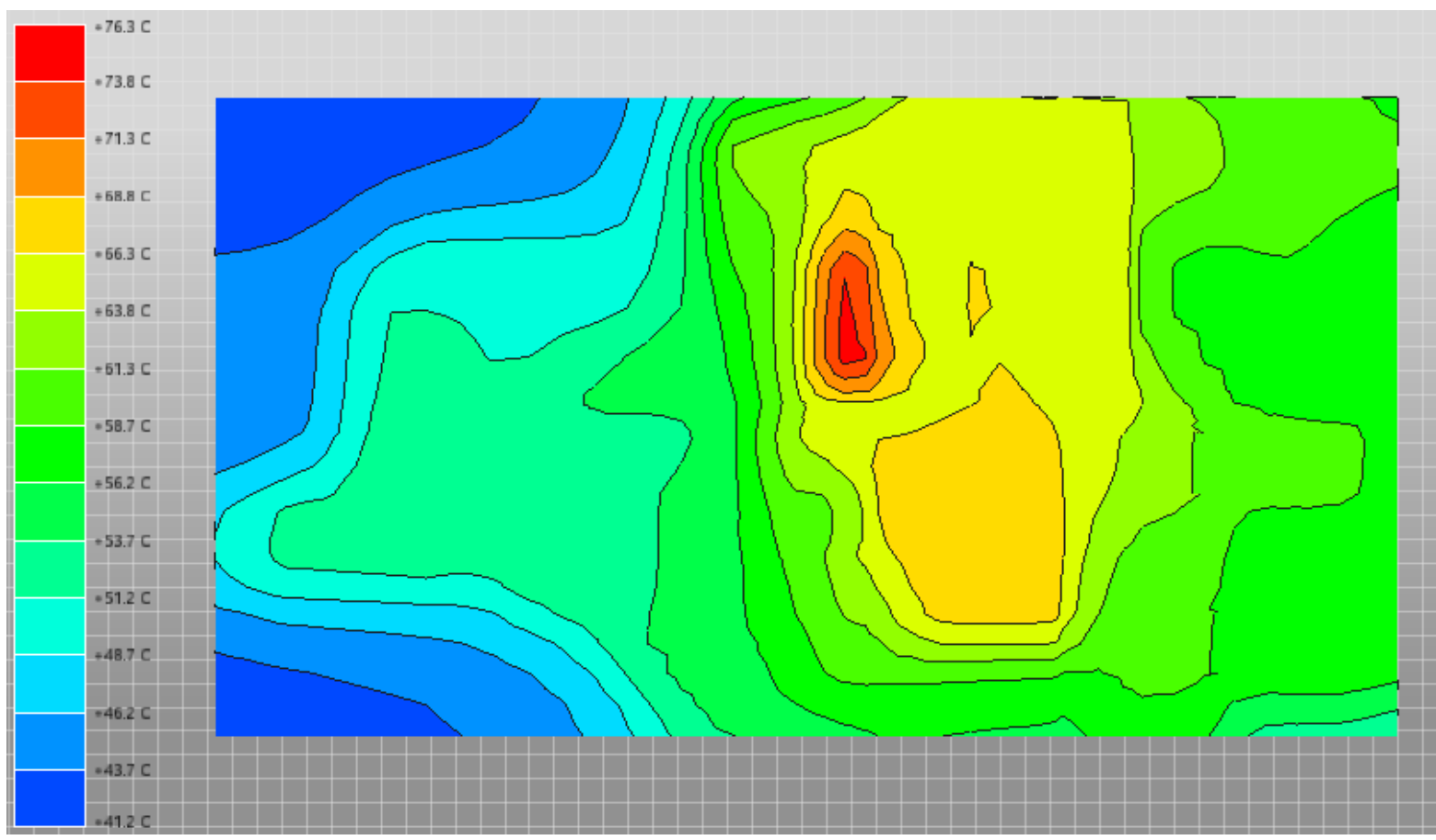

(b) at $40^{\circ} \mathrm{C}$ ambient temperature

Figure 7. The temperature distribution on PCB.

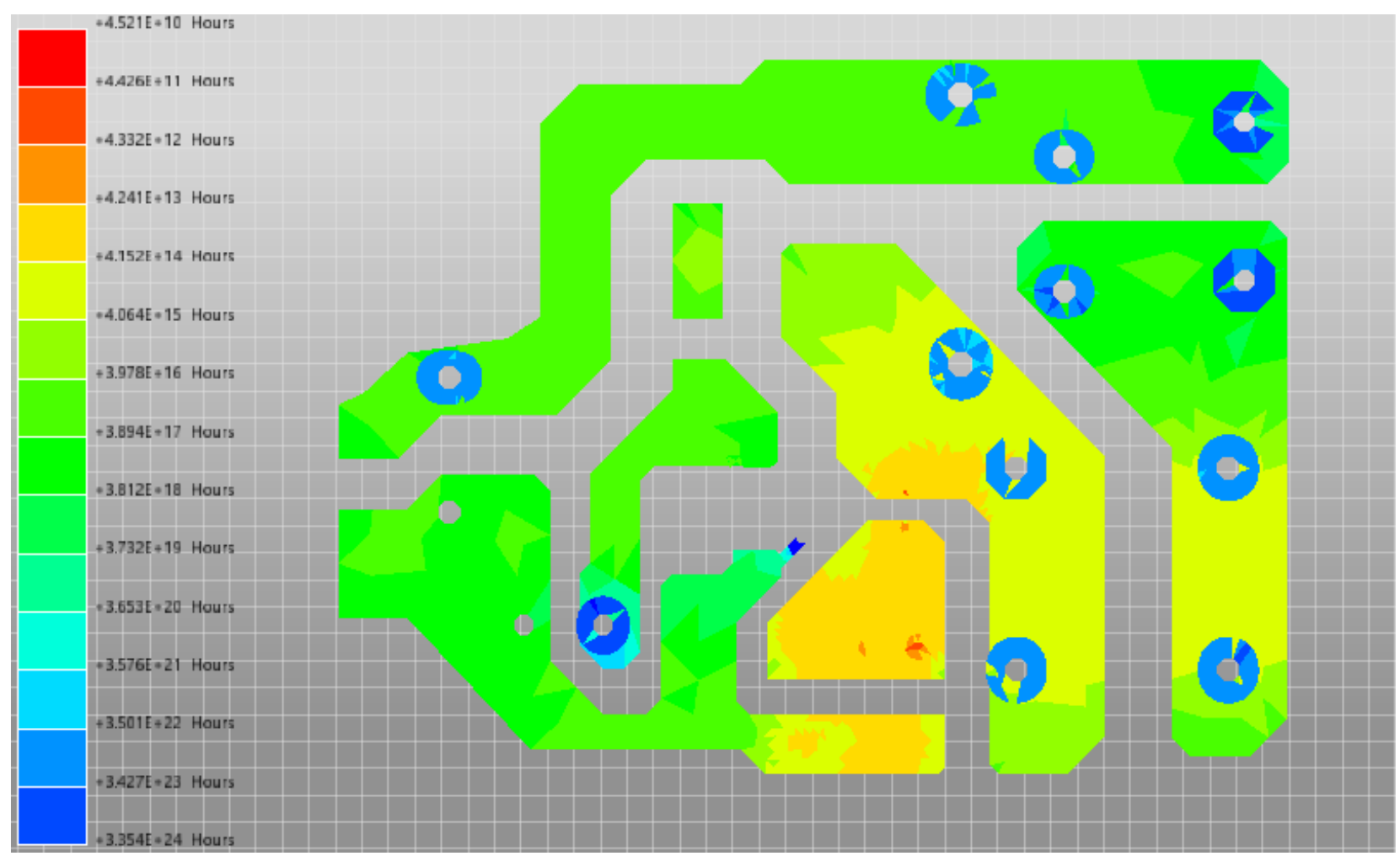

Figure 8. MTTF in condition $25^{\circ} \mathrm{C}$ ambient temperature.

$\mathrm{J}$ on the conductor and the temperature ( $\mathrm{T}$ parameters). Because Black's Equation is considering the current density ( $\mathrm{J}$ - unit is $\left.\mathrm{A} / \mathrm{cm}^{2}\right)$ that flows through the conductor cross-section, 


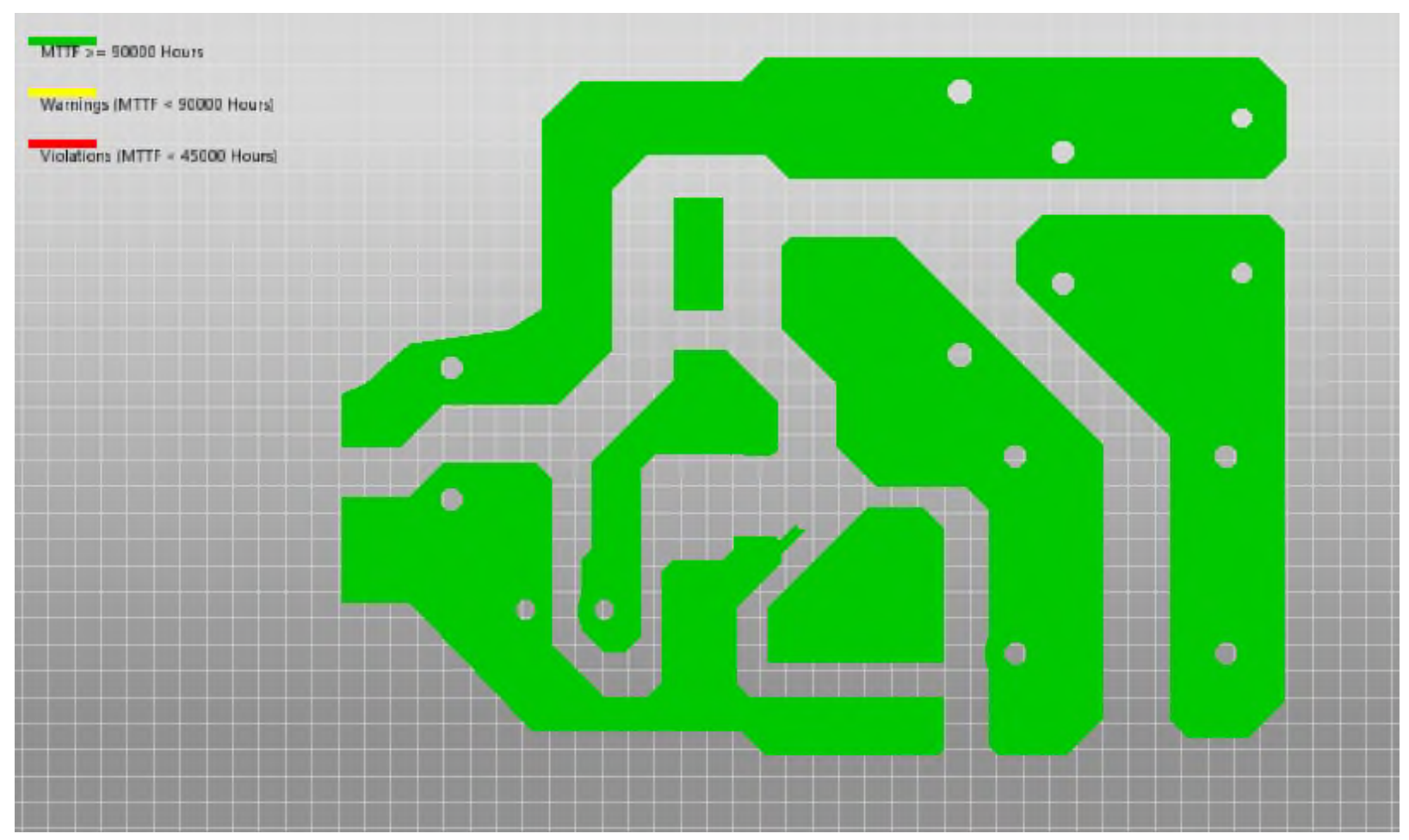

Figure 9. MTTF Warnings/Errors Map.

and the energy (Ea) needed to produce electron migration, the latter does not need to be expressed in unit volume. Ea, $\mathrm{n}$ is difficult to estimate because depending on the material and usage situation.

Under test conditions of $25^{\circ} \mathrm{C}$, the value of $n$ was chosen to be 1.5 and reference to the activation energy of copper $\mathrm{Ea}(\mathrm{Cu})$ are $0.84 \mathrm{eV}$. In the case of setting a warning when MTTF $<90,000$ hours and an error when MTTF $<45,000$ hours, it can be seen that the board is well designed, without any warning at any location.

\section{Conclusion}

The approach developed in this paper provides a novel methodology, and it is applicable for other types of LED drivers.

Moreover, in the future study, the stochastic process of LED's degradation can be integrated with electronic-thermal simulation to obtain the power dissipation directly.

\section{Acknowledgments}

This research has been supported by Advantech., JSC. We thank our colleagues from Electrical and Electronics Department, Hanoi
University of Mining and Geology, Vietnam who provided insight and expertise that greatly assisted the research.

\section{Author contributions}

Si Tien Nguyen contributes to the idea, data acquisition, analysis, and writes the manuscript. An Dinh Pham contributed to the methodology.

\section{References}

J. Huang, D. S. Golubovic, S. Koh, D. Yang, X. Li, X. J. Fan, and G. Q. Zhang. (2015). Degradation mechanisms of mid-power white-light LEDs under high-temperature-humidity conditions. IEEE Transactions on Device and Materials Reliability, 15(2), 220-228.

F. Haghighi and S. J. Bae. (2015). Reliatbility estimation from linear degradation and failure time data with competing risks under a stepstress accelerated degradation test. IEEE Transactions on Reliability, 64(3), 960-971.

C. Quian, X. J. Fan, C. Yuan, and G. Q. Zhang. (2016). An accelerated test method of luminous flux depreciation for LED luminaires and lamps. 
Reliability Engineering \& System Safety, 147, 84- 92.

R. Wu, F. Blaabejerg, H. Wang, and M. Liserre. (2013). Overview of catastrophic failures of freewheeling diodes in power electronic circuits. Microelectronics Reliability, 53(9-11), 1788-1792.

S. Lan, C. M. Tan, and K. Wu. (2014). Methodology of reliability enhancement for high power LED driver. Microelectronics Reliability, 53(6-7), 1150-1159.

Black, J. R. (1969). Electromigration - A Brief Survey and Some Recent Results. IEEE Transactions on Electron Devices, 16(4), 338347.

R. L. de Orio, H. Ceric. (2010). Physically based models of electromigration: From Black's equation to modern TCAD models. Microelectronics Reliability journal
W. D. van Driel and X. J, Fan. (2012). Solid state lighting reliability: components to system. Springer. New York, 628 pages

Pradeep Lall, Peter Sakalaukus, and Lynn Davis. (2015). Reliability and Failure Modes of SolidState Lighting Electrical Drivers Subjected to Accelerated Aging. IEEE. Translations and content mining are permitted for academic research only. IEEE Access (3), 2169-3536

Michael Riebling, Philips Hadco and OptoElectronix David Szombatfalvy. (2011). LED Luminaire Lifetime: Recommendations for Testing and Reporting Solid-State Lighting Product Quality Initiative Third. Next Generation Lighting Industry Alliance (NGLIA) formed SSL Quality Advocates and a Reliability and Lifetime Working Group, 35 pages. 